\title{
A system dynamics approach for water resources policy analysis in arid land: a model for Manas River Basin
}

\author{
ShanShan $\mathrm{DAI}^{1}$, LanHai $\mathrm{LI}^{2,3 *}$, HongGang $\mathrm{XU}^{4}$, XiangLiang PAN ${ }^{2}$, XueMei $\mathrm{LI}^{2,3}$ \\ ${ }^{1}$ Faculty of Hospitality and Tourism Management, Macau University of Science and Technology, Macau 999078, China; \\ ${ }^{2}$ State Key Laboratory of Desert and Oasis Ecology, Xinjiang Institute of Ecology and Geography, Chinese Academy of Sciences, \\ Urumqi 830011, China; \\ ${ }^{3}$ Xinjiang Key Lab of Water Cycle and Utilization in Arid Zone, Xinjiang Institute of Ecology and Geography, Chinese Academy of \\ Sciences, Urumqi 830011,China; \\ ${ }^{4}$ School of Tourism Management, Sun Yat-sen University, Guangzhou 510275, China
}

\begin{abstract}
The Manas River Basin in Xinjiang Uygur autonomous region, similar to other arid regions, is facing water constraints which challenge decision-makers as to how to rationally allocate the available water resources to meet the demands from industries and natural ecosystems. Policies which integrate the supply and demand are needed to address the water stress issues. An object-oriented system dynamics model was developed to capture the interrelationships between water availability and increasing water demands from the growth of industries, agricultural production and the population through modeling the decision-making process of the water exploration explicitly, in which water stress is used as a major indicator. The model is composed of four sectors: 1) natural surface and groundwater resources; 2) water demand; 3) the water exploitation process, including the decision to build reservoirs, canals and pumps; 4) water stress to which political and social systems respond through increasing the supply, limiting the growth or improving the water use efficiency. The model was calibrated using data from 1949 to 2009 for population growth, irrigated land area, industry output, perceived water stress, groundwater resources availability and the drying-out process of Manas River; and simulations were carried out from 2010 to 2050 on an annual time step. The comparison of results from calibration and observation showed that the model corresponds to observed behavior, and the simulated values fit the observed data and trends accurately. Sensitivity analysis showed that the model is robust to changes in model parameters related to population growth, land reclamation, pumping capacity and capital contribution to industry development capacity. Six scenarios were designed to investigate the effectiveness of policy options in the area of reservoir relocation, urban water recycling, water demand control and groundwater pumping control. The simulation runs demonstrated that the technical solutions for improving water availability and water use efficiency are not sustainable. Acknowledging the carrying capacity of water resources and eliminating a growth-orientated value system are crucial for the sustainability of the Manas River Basin.
\end{abstract}

Keywords: water resources management; sustainable development; system dynamics modeling; water stress; arid river basin

Citation: ShanShan DAI, LanHai LI, HongGang XU, XiangLiang PAN, XueMei LI. 2013. A system dynamics approach for water resources policy analysis in arid land: a model for Manas River Basin. Journal of Arid Land, 5(1): 118-131.

Water resources management is a complicated and delicate issue in regional planning and development, especially in an arid river basin where evaporation is much greater than precipitation. Technological solutions are not enough to solve water resource issues.
They must also be addressed within the social-economic system, especially the value system of the modern society. Therefore, the fundamental principle of sustainable development in an arid region is to manage the social-economic growth with the acknowledge-

\footnotetext{
*Corresponding author: LanHai LI (E-mail: lilh@ms.xjb.ac.cn) Received 2012-07-20; revised 2012-09-14; accepted 2012-10-31 (c) Xinjiang Institute of Ecology and Geography, Chinese Academy of Sciences, Science Press and Springer-Verlag Berlin Heidelberg 2013
} 
ment of the carrying capacity of limited water resources (Syme and Hatfield-Dodds, 2007).

There has been much literature on the researches of the relationship between social growth and the hydrological process (Falkenmark, 1997; Berkes and Folke, 1998; Gunderson et al., 2006). Studies employed a variety of tools and parametric assumptions to estimate water capacity associated with various engineering solutions by concentrating on achieving a rapid increase in income through accelerated growth. It is a widespread misconception that it is appropriate to solve water stress issues from the supply side. The sustainable management of water resources requires the integration of the water resource system with the regional social-economic structure (Rauch et al., 2002). Some studies addressed a coherency of them with the hydrological-social-economic system in a single analysis, but just in linear ways or limited in theory (Lindh, 1985). Constraints of time and resources, as well as the complexity of some methodologies, also limit an analyst's ability to capture the full range of economic development and water resources (Fernández and Selma, 2004), especially the groundwater system which is a determining factor for regional sustainable development. Therefore, system modeling as a methodology was used to evaluate the sustainability of the water resource system in the Manas River Basin where the water security is at an unsafe level (Ling et al., 2012).

A systematic approach to solve water shortage problem, addressing both interactive and non-linear relationships (Ohlsson and Turton, 1999), has proven to be effective (Simonovic and Fahmy, 1999; Xu et al., 2002; Tidwell et al., 2004; Gastelum Perez, 2006; Winz et al., 2009; Gastélum et al., 2010; Sánchez-Román et al., 2010). Different scenarios can be simulated to measure the effectiveness of policy (Ford, 1999). Studies dealing with water resource management is considered to be an appropriate tool for modeling both hydrological process ( $\mathrm{Li}$ and $\mathrm{Si}$ monovic, 2002; Ahmad and Simonovic, 2006) and the complex basin system from systematic perspectives (Xu et al., 2002; Fernández and Selma, 2004; Chu et al., 2009; Gastélum et al., 2010; Sánchez-Román et al., 2010). Ahmad and Simonovic (2000) developed a system dynamics (SD) model for reservoir operation and evaluated the capacity of a reservoir to handle large floods. Ahmad and Simonovic (2006) used SD to develop a decision support system for management of floods. Saysel et al. (2002) displayed the effects of salinization and water availability on regional crop yields. Xu et al. (2002) developed an SD model to evaluate the sustainability of Yellow River water resources in China. Ahmad and Prashar (2010) evaluated municipal water conservation policies using a dynamic simulation model. An SD modeling approach can also capture time delays and internal feedback loops that alter the behavior of the system (Sterman, 2000). In the water management SD models, the social and economic factors were integrated with water resources, and both the hydrological process and the economic structures were discussed (Winz et al., 2009). The effectiveness of policy interventions within the current social and economic context was also estimated, especially in the case of China (Xu et al., 2002).

This paper examined the feedback loops between social-economic development, water allocation, and water exploitation by building a system dynamics model. The interactions of the hydrological process, irrigation canals, the groundwater system, and social-economic changes were also examined. Additionally, the paper explored what the future holds for arid regions if supply-driven water exploitation strategies are maintained, and it attempts to demonstrate the impacts of water exploitation processes on natural river systems which were to meet the economic development expectation.

\section{Study area and model development}

System dynamics is a method to understand the behavior of complex systems over time (Sterman, 2000) and how endogenous structure of the system influences the behavior of the system. SD provides a conceptual framework useful in the assembly of non-linear differential equations with complex feedbacks (Forrester, 1961). The variable components are linked with each other through feedback loops, and the dynamic behavior of systems is controlled by the feedback loop structure (Senge, 1990; Richardson, 1991). Simulation models play an important role in understanding complex problems addressed in water resources management. 
An SD model is constructed by four steps: 1) model's elements: exploring the key sectors and elements of the system to shape a concept model to understand the model as a system; 2) model's boundary: discussing the elements' characters (endogenous or exogenous) and structure to determine the model's boundary to be specific about the dynamic problem; 3) model formulation: keeping track of complex interrelationships and feedback loops among elements to a more precise and detailed understanding; and 4) model validation: being calibrated and validated using a combination of primary data from field data collection and from existing literature to develop a tool that can be tested under different simulations and scenarios (Ford, 1999; Evans et al., 2001; Maani and Cavana, 2007).

\subsection{Study area and model's elements}

The Manas River Basin (MRB) is the target study area of our research. It is an arid region located to the north of Tianshan Mountains, Xinjiang Uygur autonomous region, in northwestern China. MRB lies immediately to the south of the Gurbantunggut Desert, with a drainage area of $2.29 \times 10^{4} \mathrm{~km}^{2}$. Geographically, it is composed of three parts (Fig. 1): a mountain area which provides water resources is at the south edge of the basin; an oasis where human habitation occurs at the foot of the mountains; and a desert region is directly to the north of the mountains. In 2001, the mountain area was about $7,650.91 \mathrm{~km}^{2}$ and the oasis area was about 2,696 $\mathrm{km}^{2}$ (Cheng et al., 2006). Precipitation comes primarily in the form of snow from October to March in the mountains, and the snowmelt is the main water recharge source.

This study focuses on the oasis, where the water stress comes from two sides: water supply and water demand. Water supply is constrained by surface water and groundwater volume and determined by the water exploitation capacity. Prior to 1949, fluctuations in surface water access resulted in a nomadic lifestyle for the inhabitants of the region. After 1949, large-scale land reclamation was initiated by building canals, reservoirs and pumps to increase water availability (Han, 2001). The water demand came from irrigation, industry, and residential use. Irrigation consumed the largest amount of water. Large areas of desert and swamp

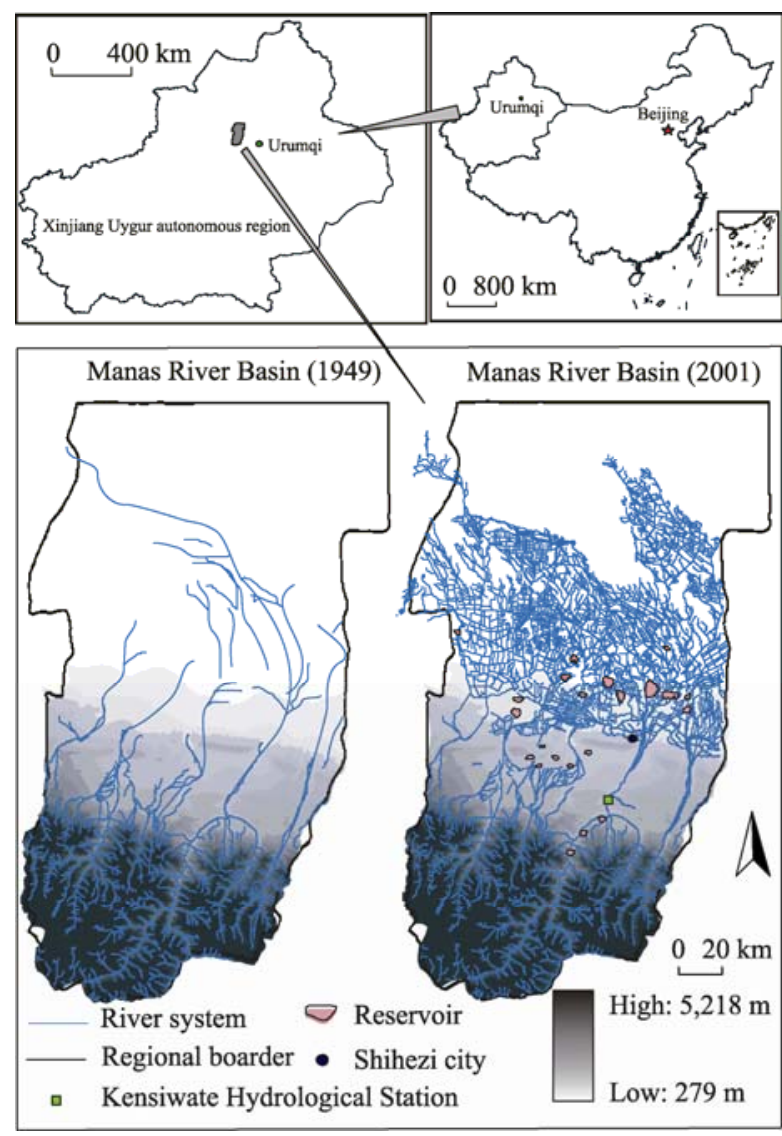

Fig. 1 The location of Manas River Basin and changes in land use and river system

were developed into cultivated land and settlements (Han, 2001). Industry development brought in immigrates and produced a greater stress on the water resources.

\subsection{Model's boundary}

There are two kinds of boundaries in system dynamic modeling: 1) "wholism", which illuminates the "enfolded" nature of reality. In this context, elements' characters should be defined, and the essence of wholism is to define the exogenous elements to enfold to nature of reality. The key elements are stocks representing where accumulation or storage takes place in the system (Forrester, 1961; Richmond, 1993; Sterman, 2000); and 2) "structuration", which suggests processes for how the structure of social systems arises (Senge, 1998). Structuration theory, which is to explore the causal diagram to demonstrate feedback relationships between stocks, draws attention to how mental models are shaped as well as how they in turn 
shape decision making.

In MRB, governmental plan controls and leads the social-economic development. In the water supply side: 1) Surface water runoff from mountains is treated as an external variable; 2) New technology, such as canals, reservoirs, water-saving projects and municipal water-recycling plans, are external variables determined by the government to enhance the available surface water; and 3) The allocation of available surface water resources is determined by the municipal government. Surface water is mainly used for irrigation, while groundwater is allocated to meet residential and industrial demands. The remaining water can then be allocated to irrigation when needed. In the water demand side, the natural birth rate is basically controlled, and population is mainly affected by immigration, which is related to economic and industrial development. There are seven key stocks, i.e. available groundwater, water stress, reservoir, pump, irrigated land, industry and population.

Figure 2 is the causal diagram demonstrating the relationships between those stocks. Four important feedback loops can be identified in the figure. The first and second balance loops (1B and $2 \mathrm{~B}$ ) show the typical supply and demand interplay (Fernández and Selma, 2004). The available water is constrained by available surface water and groundwater pumped out. An increasing demand for water heightens the water stress. At the same time, water stress restricts the expansion of irrigated land and also leads to an improvement of water exploitation technology. As a result, the amount of available water is increased.

A time delay exists between water stress and pumping capacity improvement, which means that the water stress is seldom relieved by the increase of pump numbers. The delay mainly limits land expansion. However, once the delay is eliminated, a correlation between the two negative loops appears. Water exploitation facilities constructed for increasing the amount of available water would relieve water stress, enhance land reclamation, and then encourage the development of industry. This process promotes urbanization and the establishment of municipal structures, which in turn, attracts immigrates and finally accelerates the economic development. A reinforced loop takes shape (1R).

On the other hand, rapid pump development has resulted in the overexploitation of groundwater (3B) and has decreased the maximum volume of available groundwater in the long term. This loop makes the system fall into a "fixes that fail" situation (Senge, 1990).

\subsection{Model formulation}

\subsubsection{Water resources}

1) Surface water: Water resources in MRB begin

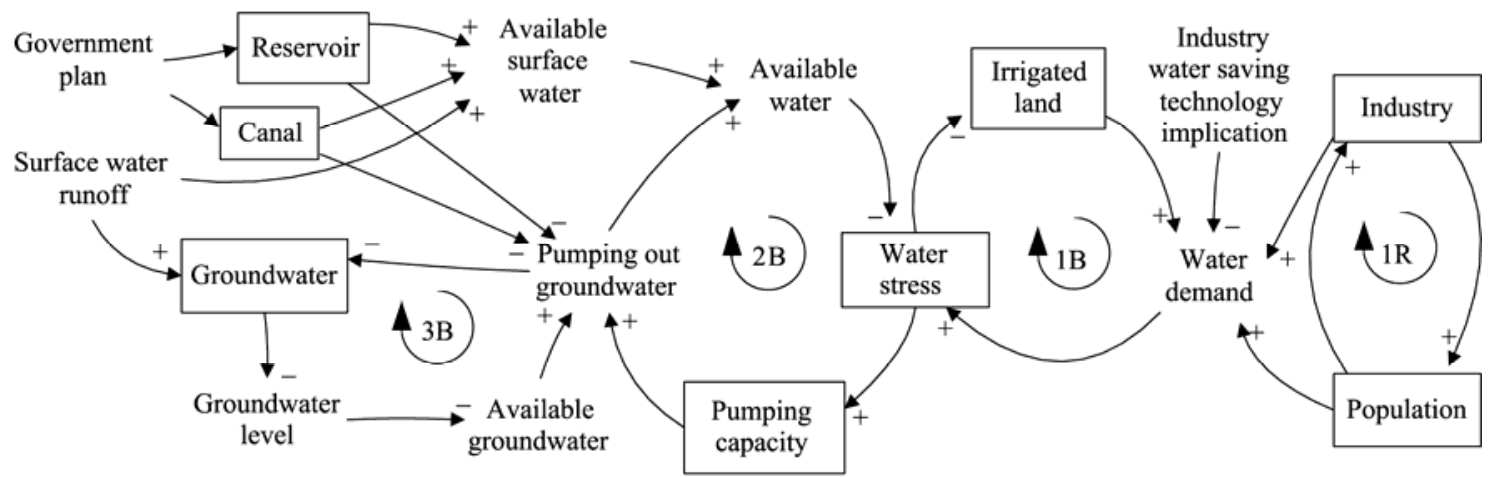

- Causal- effect relationship

+ Positive relationship

- Negative relationship

(1R) Reinforced feedback
(1B) Balanced feedback

2B) Balanced feedback

3B Balanced feedback

Fig. 2 The relationships among the key elements and the feedback loops 
in the mountainous region and later become surface runoff. Surface water $\left(V_{s w}\right)$ data were gathered at Kensiwate Hydrological Station located at the mountain foot and recorded the volumes of surface water running from the mountain to the oasis. The average runoff was $1,172 \mathrm{Mm}^{3} /$ a from 1956 to 1996, accounting for about $52 \%$ of the total water resources in MRB. It can be observed that a minimum annual runoff of 935 $\mathrm{Mm}^{3}$ occurred in 1992 and a maximum of 1,470 $\mathrm{Mm}^{3}$ happened in 1966.

2) Groundwater: Groundwater is the main water supply for municipal water use and contributes a lot to land reclamation. The groundwater recharge mainly comes from reservoir leakage, canal leakage, mountain recharge and the leakage from irrigated lands. Flood interflow seepage is relatively small. Over exploitation has resulted in decreased groundwater recharge, and also induced the decline of water table. From 1964 to 1993, due to the long-term exploitation of groundwater, the groundwater level dropped by about 12.58 to $17.06 \mathrm{~m}$ in Shihezi city, and there was an average annual decreasing rate of $0.17 \mathrm{~m}$ in the west of Manas county (Cheng, 2003). Some areas began to explore deep groundwater.

The groundwater resource would be aggregated into a single aquifer in the model (de Marsily, 1986). Groundwater resource is a stock increased by recharge and decreased by drainage and pumping:

$$
\begin{gathered}
V_{g w}[t]=V_{g w}[t-1]+\left(R_{g w}-L_{g w}-V_{p}\right) \times d t, \\
R_{g w}=\operatorname{Max}\left(\operatorname { M i n } \left(V_{v s f} \times k_{c g w}+V_{t m w} \times k_{m g w}+\right.\right. \\
\left.\left.V_{r} \times k_{r g w}+V_{i} \times k_{i g w}, C_{g w}-V_{g w}\right), 0\right) .
\end{gathered}
$$

Where $V_{g w}(t)$ is the volume of groundwater in time $t$, $R_{g w}$ groundwater recharge, $L_{g w}$ groundwater drainage, $V_{p}$ the volume of groundwater pumped out; $k_{c g w}, k_{m g w}$, $k_{\text {rgw }}$ and $k_{\text {igw }}$ are the ratios of recharge from canal, mountain, reservoir and irrigation to groundwater, respectively; $V_{v s}, V_{t m w}, V_{r}$ and $V_{i}$ are the volume of surface water, mountain-formed water resource, water in reservoirs and water for irrigation, respectively; and $C_{g w}$ is groundwater capacity.

Surface water recharge is equal to the volume of surface water multiplied by the canal seepage coefficient, because after 1949 water allocation became dependent on canal construction and water was diverted into the irrigation canals or reservoirs after it had run down from the mountain. Over the recent several decades, due to the continuous improvement of channel anti-seepage technology, the coefficient showed a tendency to decline to 0 while the groundwater demand has kept rising. In 1990, the canal seepage coefficient was between 0.38 and 0.42 (Survey and Design Institute of Xinjiang Production and Construction Corps, 1997). On the irrigation aspect, flood irrigation was gradually changed to dripping irrigation in order to enhance water resource utility with the increase in cultivated land. Mountain recharge ratio and reservoir leakage ratio were fixed as 0.043 and 0.13 , respectively, according to historical records (Survey and Design Institute of Xinjiang Production and Construction Corps, 1997). The groundwater recharge is constrained by groundwater capacity. When its amount surpasses the capacity, surplus would recharge the Manas River in the downstream. Since the groundwater table kept declining, the Manas River dried up between 1974 and 1976 (Cheng et al., 2006).

Groundwater drainage is equal to the amount of groundwater multiplied by groundwater draining rate. And the draining rate is determined by the groundwater level. When the groundwater level decreases to the critical point, no water can be drained:

$$
L_{g w}=k_{\text {lgw }} \times V_{g w} \text {. }
$$

Where $L_{g w}$ is the volume of groundwater drainage, and $k_{\text {lgw }}$ is groundwater draining rate.

The volume of groundwater pumped out $\left(V_{p}\right)$ is constrained by the pumping capacity and the available groundwater $\left(V_{a g w}\right)$. The available groundwater, which is only a part of groundwater reserve, is determined by the groundwater level $\left(V_{g l}\right)$ (de Marsily, 1986) and constrained by the maximum available groundwater $\left(V_{\text {magw }}\right)$. The available data for all local aquifers allow the characterization of such an aggregated aquifer in the model. The available groundwater will decrease sharply when the groundwater level begins to decline, due to the shape of the aquifer, which is like an inverted cone. The relationship between the groundwater level and available groundwater is simulated by a logistic curve (de Marsily, 1986). No more water can be pumped out when groundwater level has declined below a certain threshold. 


\subsubsection{Water exploitation facilities}

1) Reservoir: There are seventeen reservoirs in the Manas region. Most reservoirs are built in the oasis area. Evaporation is much higher than precipitation. Water in reservoirs is allocated to irrigated land when needed. The water in the reservoirs is a stock recharged by the inflow from surface water. The water is withdrawn by outflow for irrigation, reservoir leakage, and evaporation:

$V_{r}[t]=V_{r}[t-1]+\left(R_{s w r}-L_{r i}-\left(k_{r e}+k_{r g w}\right) \times R_{s w r}\right) \times d t .(4)$

Where $V_{r}(t)$ is the volume of water in reservoir, $R_{s w r}$ the inflow from surface water, $L_{r i}$ the water for irrigation, and $k_{r e}$ and $k_{r g w}$ the ratios of reservoir evaporation and reservoir leakage, respectively.

The inflow is constrained by the reservoir's capacity and available surface water. When storage exceeds the reservoir's capacity, spillover occurs. The evaporation coefficient is based on the data of 1990 when average evaporation losses are gained by multiplying the water volume in the reservoir with 0.1 .

2) Pumping capacity: Pumping capacity changes with the construction or decrease of pumps. Pump construction is influenced by two main factors, municipal water demand and irrigation water demand from pumping, and constrained by the perceived groundwater shortage. Pumps become idle when pumping water capacity is beyond the availability of groundwater, and there is also natural depreciation:

$$
\begin{gathered}
C_{p w}[t]=C_{p w}[t-1]+\left(R_{p}-L_{p}\right) \times d t, \\
R_{p}=\operatorname{Max}\left(\operatorname{Min}\left(\left(P_{i p}+D_{m w}-C_{p w}\right) / t_{p}, P_{g w s}\right), 0\right), \\
L_{p}=L_{n p}+\left(C_{p w}-V_{a g w}\right) / t_{p} .
\end{gathered}
$$

Where $C_{p w}(t)$ is the water pumping capacity, $R_{p}$ and $L_{p}$ the water volumes from pump construction and pump depreciation respectively, $P_{i p}$ the irrigation water demand from pumping, $D_{m w}$ municipal water demand, $t_{p}$ the time cost of pump construction, $P_{g w s}$ the impact of perceived groundwater shortage on pumping, $L_{n p}$ natural depreciation, and $t_{p}$ the time cost for pump depreciation when pumps become idle.

Perceived groundwater shortage, or foreseen limited opportunity to get water, would terminate pumping even when the water stress is severe. This index is measured by the utilization rate of the pumping facility:

$$
V_{g w s}[t]=\left(\left(C_{p w}-V_{p}\right) / C_{p w}\right) / t_{g w s} .
$$

Where $V_{g w s}$ is the perceived groundwater stress, and $t_{g w s}$ the time cost for groundwater shortage perception.

\subsubsection{Water demand}

1) Land reclamation and irrigation demand: Irrigation represents the highest demand for water. The area of irrigated land is a stock. It increased rapidly via land reclamation when canals and reservoirs were built to increase water utilization. Up until 1962, the oasis area was 18.8 times larger as that in year 1949 (156 $\mathrm{km}^{2}$ ) (Tang et al., 1992). After 1989, reclamation tended to be reduced because of the limitation of water resources.

$$
\begin{aligned}
& V_{i l}[t]=V_{i l}[t-1]+\left(R_{i l}-L_{i l}-R_{m l}\right) \times d t . \\
& R_{i l}=\operatorname{IF}\left(G_{i w}>0\right), \\
& \text { then }\left(\min \left(G_{i w} /\left(t_{i e} \times k_{i w d}\right), V_{u l}\right)\right) \operatorname{else}(0) \\
& L_{i l}=\operatorname{IF}\left(G_{i w}<0\right), \\
& \text { then }\left(\min \left(G_{i w} /\left(t_{i r} \times k_{i w d}\right), V_{i l}\right)\right) \operatorname{else}(0) \text {. }
\end{aligned}
$$

Where $V_{i l}$ is the area of irrigated land, $R_{i l}$ the explored irrigated land in year $t, L_{i l}$ the irrigated land return in year $t, R_{m l}$ the area of municipal land increase in year $t$, $G_{i w}$ the gap between available water for irrigation and irrigation demand, $t_{i e}$ and $t_{i r}$ the time costs for irrigated land reclamation and return respectively, $k_{i w d}$ water demand per irrigated land, and $V_{u l}$ the area of unused land which is $15,321 \mathrm{~km}^{2}$ initially. Water available for irrigation includes three parts: surface water, groundwater and municipal wastewater discharge. The total municipal wastewater discharge was approximately $53 \mathrm{Mm}^{3}$ in 1990 (Survey and Design Institute of Xinjiang Production and Construction Corps, 1995).

Irrigation demand per land area is impacted by two factors: crop type and irrigation technology:

$$
\begin{aligned}
D_{i w} & =V_{i l} \times k_{i w d}, \\
K_{i w d} & =k_{\text {piwd }} \times V_{i t} .
\end{aligned}
$$

Where $D_{i w}$ is irrigated land water demand, $k_{\text {piwd }}$ the basic parameter for water demand per irrigated land, and $V_{i t}$ the irrigation technology index. The average annual irrigation water demand, under the assumption that it was the same over all crops, was about 0.51 $\mathrm{Mm}^{3} / \mathrm{km}^{2}$ in 1990 (Survey and Design Institute of Xinjiang Production and Construction Corps, 1995). 
2) Industry water demand: Industry output growth is dependent upon capital investment, labor force and technology, and is based on an assumption that all investments are autonomous, and a part of the industry output is used for reinvestment (Chow and $\mathrm{Li}, 2002$ ). Industry water demand is obtained by multiplying industry output with per capita industry water demand, which is assumed to have a negative correlation with industry technology.

These can be formulated as follows:

$$
\begin{gathered}
V_{i o}=V_{i o t} \times\left(V_{w f}^{\left(1-k_{c c}\right)} \times V_{i c}^{k_{c c}}\right), \\
V_{i c}[t]=V_{i c}[t-1]+\left(V_{i o} \times k_{o i}-L_{i c}\right) \times d t, \\
D_{i n w}=V_{i n} \times k_{i n w d}, \\
K_{i n w d}=k_{\text {pinwd }} \times V_{i o t} .
\end{gathered}
$$

Where $V_{i o}$ is industry output, $V_{\text {iot }}$ industry technology which is an external variable, $V_{w f}$ the work force, $k_{c c}$ capital contribution to industry development, $V_{i c}$ the industry capital, $k_{o i}$ output-investment ratio (calibrated as 0.33 ), $L_{i c}$ capital depreciation, $D_{i n w}$ industry water consumption, $k_{i n w d}$ per capita industry water demand, and $k_{\text {pinwd }}$ the basic parameter for per industry water demand. Most users are utilizing public water supply while some major users are adopting self-supplied wells now. Therefore, there are no accurate data on the water consumption of the industrial sector. It is estimated from the other cities in Northwest China (Survey and Design Institute of Xinjiang Production and Construction Corps, 1995).

3) Residential water demand: The human population started to boom after 1949 since modern technologies were implemented to increase the accessibility to water resources. After 1979, the population increase tended to level off because of the birth control policy. But population growth trend resumed after 1990 because of the development of economy. The population is a stock adjusted by both natural growth and immigration. The immigration rate is affected by job availability, especially in the industrial sector.

$$
\begin{gathered}
V_{m}[t]=V_{m}[t-1]+\left(R_{m}-L_{m}+R_{\text {mig }}\right) \times d t, \\
R_{\text {mig }}=V_{\text {io }} / k_{\text {iom }}+V_{\text {ir }} / k_{\text {irm }} .
\end{gathered}
$$

Where $V_{m}$ is the population, $R_{m}$ and $L_{m}$ birth number and death toll respectively, $R_{\text {mig }}$ migration, $k_{\text {iom }}$ work force demand per unit industry output, and $k_{\text {irm }}$ work force demand per unit irrigated land.

The impact of water resources on immigration is not considered, because residential water demand could be guaranteed in advance.

Municipal water consumption includes two water usages, i.e. household water consumption and urban facility water demand, which account for roughly $30 \%$ of the residential water consumption. It is calculated by multiplying the population with per capita water consumption:

$$
\begin{aligned}
D_{m w} & =V_{m} \times k_{m w d}, \\
K_{m w d} & =k_{p m w d} \times V_{m t} .
\end{aligned}
$$

Where $D_{m w}$ is municipal water consumption, $k_{m w d}$ per capita water demand, $k_{p m w d}$ the basic parameter for per capita water demand, and $V_{m t}$ the municipal technology index. Per capita water demand was $54 \mathrm{~L}$ in 1978 and $160.5 \mathrm{~L}$ in 1999 (Statistics Bureau of Xinjiang Uygur Autonomous Region, 1990-2007; Office of the Xinjiang Uygur Autonomous Regional Committee, Xinjiang Uygur Autonomous Region People's Government Office, 2005).

\subsubsection{Water stress}

The perceived water stress, which is the interaction between irrigation water demand and water supply, is obtained by dividing available water with water demand.

$$
V_{w s}[t]=V_{w s}[t-1]+\left(D_{i w} / S_{i w}-V_{w s}\right) / t_{w s} \times d t .
$$

Where $V_{w s}$ is perceived groundwater shortage, $D_{i w}$ irrigation water demand, $S_{i w}$ available water for irrigation, and $t_{w s}$ the time cost for water stress apperceiving.

The impact of water stress is mainly on irrigated land since the industry and residential water demands are guaranteed in advance while municipal water demand is relatively small (accounting for merely $0.5 \%$ ). Water stress is released mainly through improving water pumping capacity to enhance the availability of water. Stress gets higher when irrigated water demand approaches the available water for irrigation, and reaches a climax when water demand exceeds the available amount. 


\subsection{Model calibration and application}

The STELLA 9.0 platform (Wallis, 1997) was chosen for model development and implementation. The model operated on an annual time step, encompassing the period 1949-2050, which includes a 61-year calibration period (1949-2009) and then prescribes a 41-year planning horizon (2010-2050).

Most model parameters and initial values are determined by the information collected. Those parameters that could not be derived from the literature and field observations were calibrated through repeated simulations until satisfactory agreements between predicted and observed variables were obtained (Li and Simonovic, 2002; Li and Yakupitiyage, 2003). For dealing with changes in multiple parameters, the sensitivity analysis was used to guide the selection of parameters during calibration, i.e. starting with the most sensitive parameter, and then less sensitive parameters. Both qualitative and quantitative methods were used to collect and analyze the data, which were collected from four sources: published government documents, published journals, informal semi-structured interviews and field observations. Tang et al. (1992) and Han (2001) explored the land use change due to water use variation during the period 1950-1977. Yuan et al. (1995) and Cheng et al. (2006) provided the historical patterns of land use and water resources over the past 50 years of oasis development. The government documents used in this study are mainly the Shihezi County Annals (Compiling Committee of Shihezi County Annals, 1994), Shihezi Water Conservancy Annals (Shihezi Electricity and Water Authority, Manasi River Management Office, 1992) and General Report on the Manasi River Basin Water Resources Use Planning (Survey and Design Institute of Xinjiang Production and Construction Corps, 1995) which provided details of the implementation of irrigated land exploration, industrial development and urban expansion, as well as early demographic and agricultural data in MRB. Most recent data were derived from Xinjiang Statistical Yearbooks 1990-2007 (Statistics Bureau of Xinjiang Uygur Autonomous Region, 1990-2007) and Xinjiang Production and Construction Corps
Statistical Yearbooks 1990-2007 (Statistics Bureau of Xinjiang Production and Construction Corps, Survey Organization of the Corps of National Statistics Bureau, 1990-2007).

The model confidence was validated through testing the model's structure and behaviors (Ruth and Hannon, 1994). It is necessary to test model structure for examining its conceptions and internal logic (Rykiel Jr, 1996). Tests of model behaviors evaluate the adequacy of behaviors generated by the structure (Forrester, 1961; Sterman, 2000) including behavior reproduction and behavior prediction. The family of behavior reproduction tests examines how well behaviors generated by the model match the observed behaviors of the real system. Point-by-point comparisons of the behavior model is a widespread "accepted symptom generation test” (Naylor et al., 1967).

Figures 3-5 showed that the expansion of irrigated land, demographic dynamics, industrial development, the drying-out of Manas Lake, the decreasing availability of groundwater resources, the increasing perceived groundwater shortage and water stress are all adequately simulated by the model. The comparison of results from simulation and observation showed that the model corresponds to observed behaviors and the simulated values fit the observed data and trends accurately. The model is able to capture the trends of water and economic dynamics and it can also be used for simulating future behaviors.

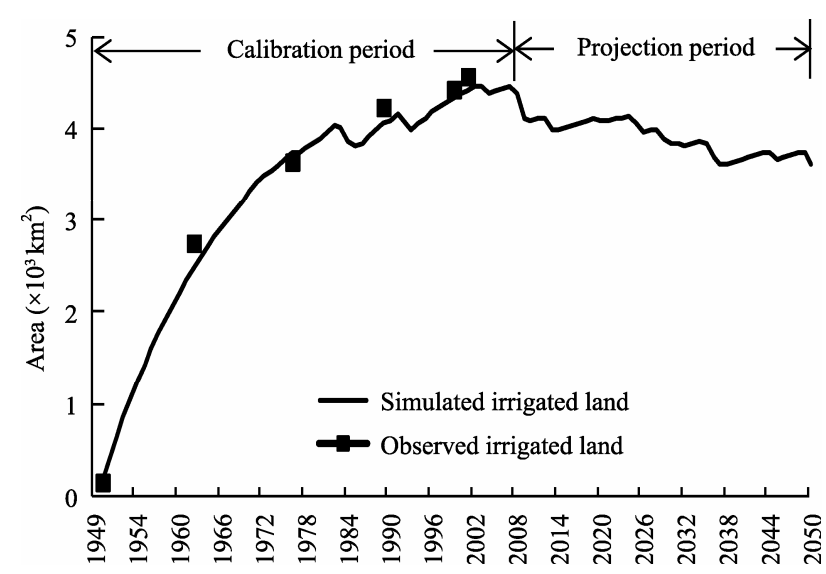

Fig. 3 Comparison between observed and simulated irrigated lands 


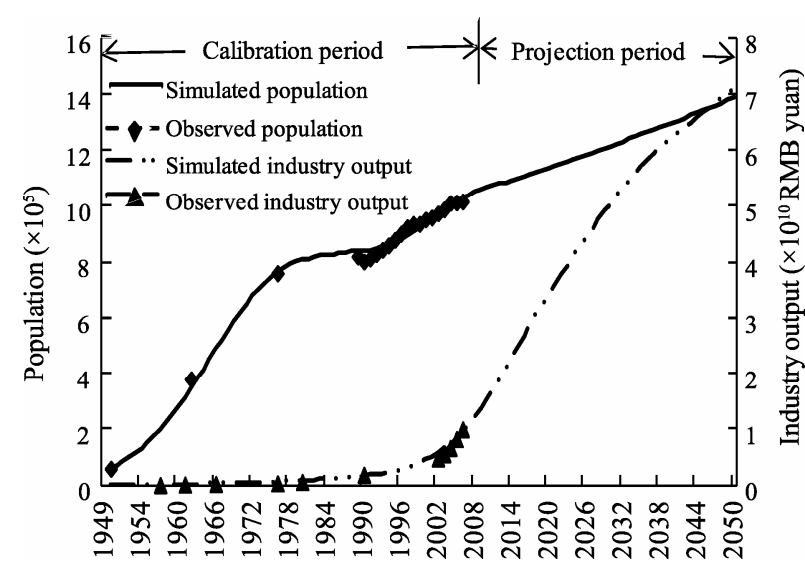

Fig. 4 Comparison between observed and simulated population and industry output

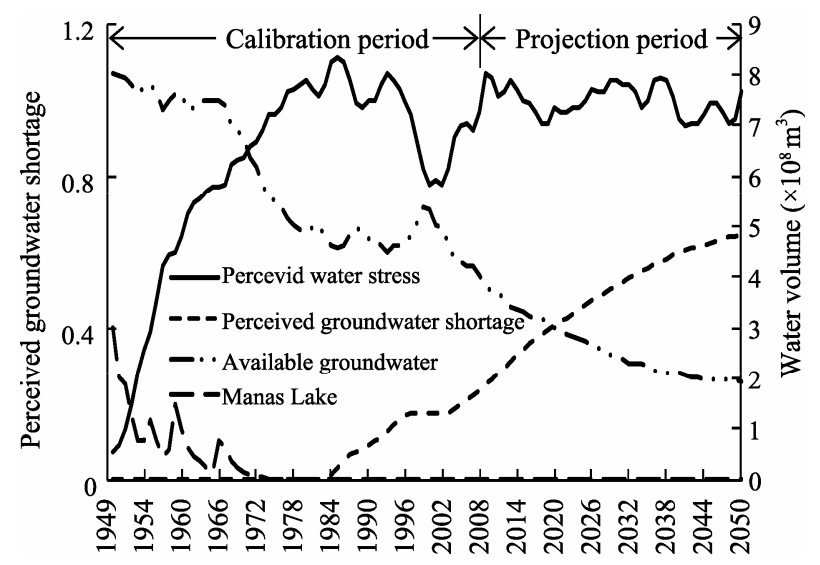

Fig. 5 Decreasing available groundwater resources and the drying-out process of Manas River

In order to ensure the integrity of the system dynamics model and demonstrate the manners in which model structure and feedback connections determine simulated behavior, the study performed sensitivity analysis by changing the value of one model parameter at a time and comparing the responses of selected target variables to the parameter changes. Following $\mathrm{Li}$ and Simonovic (2002), changing the selected parameters by about $\pm 10 \%$ of baseline value in sensitivity analysis was committed. This study took the calibration period as a base case and parameters related to the surface water supply, and selected irrigation and municipal water demand as parameters and the volume of groundwater, the area of irrigated land and water stress as target variables for the sensitivity analysis.

As shown in Table 1, all the three variables are not sensitive to the selected parameter variations. The in- fluence of the selected parameter variations on groundwater is small (below $0.4 \%$ ), whereas it varies on the area of irrigated land and water stress. The variations in the values of $V_{s w}, k_{\text {piwd }}$ and $k_{\text {piwd }}$ have little influence on the area of irrigated land. Sensitivity analysis showed that the model robustness changed with model parameters such as surface water supply, groundwater capacity, population growth rate, capital contribution to industry development capacity, and industry output-investment ratio. The results demonstrated that the SD model's dynamic behavior patterns are generated by the structure of the system. Overall, the results of calibration and sensitivity analysis showed the reliability of the model to reproduce the historic changing modes in population, land reclamation, and groundwater.

Table 1 Sensitivity analysis of the model

\begin{tabular}{ccccc}
\hline \multirow{2}{*}{ Parameter } & Change & $\begin{array}{c}\text { Groundwater } \\
\text { change }\end{array}$ & $\begin{array}{c}\text { Irrigated land } \\
\text { change }\end{array}$ & $\begin{array}{c}\text { Water stress } \\
\text { change }\end{array}$ \\
\cline { 2 - 5 } & \multicolumn{4}{c}{$(\%)$} \\
\hline \multirow{2}{*}{$V_{\text {sw }}$} & -10 & -0.405 & -6.304 & 5.805 \\
& +10 & 0.326 & 5.536 & -5.303 \\
$R_{m}$ & -10 & 0.006 & 0.54 & -0.036 \\
& +10 & -0.009 & -0.835 & 0.006 \\
$k_{c c}$ & -10 & 0.013 & 1.701 & -0.174 \\
& +10 & -0.031 & -3.455 & 0.169 \\
$k_{\text {oi }}$ & -10 & 0.001 & 0.119 & 0.002 \\
& +10 & -0.001 & -0.116 & -0.010 \\
$k_{\text {mwd }}$ & -10 & 0.005 & 0.438 & -0.027 \\
& +10 & -0.005 & -0.466 & 0.018 \\
$k_{\text {piwd }}$ & -10 & 0.001 & 10.877 & -0.184 \\
& +10 & -0.001 & -8.899 & 0.436 \\
\hline \multirow{3}{*}{} & & & &
\end{tabular}

\section{Results and discussion}

\subsection{Basic scenario of future projection}

To be useful, a future projection with a businessas-usual assumption must be conducted in the context of the past. Specifically, the post-2007 surface water flows were generated on 1956-1996 data. This provides a base to project the future, such as the growth trends of population and industry. The area of irrigated land and the volume of groundwater were chosen to measure further policy scenarios.

The results of the model projection from 20102050 in Figs. 3-5 are as follows: 
1) The amount of irrigated land will slightly decrease with fluctuations. This decrease is caused by the decreased level of groundwater. The level is limited because the use of the modern technology makes it possible to increase the water use efficiency. The system would be sustainable, which is a consequence of surface water as an exterior variable (Fig. 3).

2) The natural birth and death rates are almost the same under the birth control policy. However, the population keeps rising, which is a result of economic development and increased immigration. By 2050, the population will be about 1.38 million, which is 23 times more than that in 1949 (Fig. 4).

3) Industry output growth will continue at an exponential rate. There is a relatively small chance that constraints will prohibit industrial growth (Fig. 4).

4) The continuous growth of population and industry will result in more water consumption and it means groundwater will continue to be explored. As a result, the available groundwater resources are reducing, and the perceived groundwater shortage keeps rising. This phenomenon implies that the water saving from improving water utilization technology and water exploitation from groundwater is not able to meet the water demand due to rapid economic development (Fig. 5).

\subsection{Policy implications}

For public and political leaders, a useful model should explain the causes of important problems and provide a basis for policy designing that can improve behavior in the future. The model provides a platform for constructing alternative water exploitation and allocation strategies in the context of the economic development in arid regions.

Six scenarios are designed to provide a quantitative basis for comparatively evaluating the effects of improving water utilization on economic development and water resource sustainability:

Scenario 1: Basic scenario (See 2.1).

Scenario 2: Reservoir building. This scenario focuses on water conservation, and is based on a government plan which is to build a big reservoir at the foot of the mountain to substitute the present reservoirs in the oasis area in order to decrease reservoir evaporation and leakage.
Scenario 3: Urban water recycling. This scenario assumes that the urban water recycling rate would be increased by 5 times. The urban water recycling project is suggested in many regional development plans. This scenario is intended to examine the potential impacts of water saving.

Scenarios 4, 5 and 6: Water demand control. These three scenarios focus on the water demand. The fourth one is the change in irrigation water demand per area (20\% reduce as the basic run). The other two are the changes in industrial water demand per capita (50\% reduce and 50\% enhance as the basic run). Xinjiang is faced with new opportunities to boost its economy. The change of industrial multiplicity would alter the industrial water consumption rate. These scenarios are intended to assess the potential economic development capacity under economic uncertainties.

Scenario 7: Groundwater pumping control. This scenario suggests controlling groundwater pumping in order to achieve sustainable water use. This scenario assumes that water pumping is forbidden after 2010, and is intended to provide a backdrop for evaluating the impact of water pumping and to test the renovation capacity of the groundwater system.

\subsection{Results of alternative scenarios}

The perceived water stress, irrigated land, and groundwater volume were chosen as indexes for evaluating the impacts of the scenarios. Figures 6-8 showed the trends of the selected indexes under the alternative scenarios.

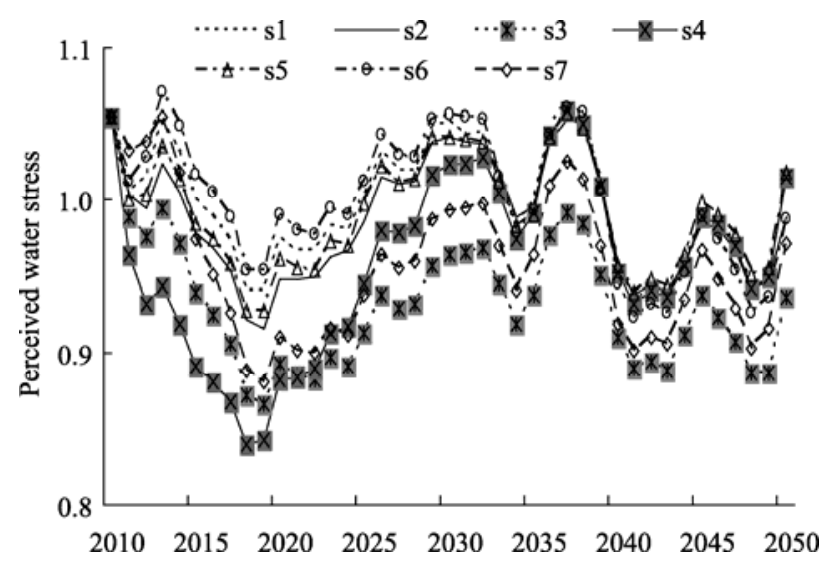

Fig. 6 Comparison of the perceived water stress under seven alternative scenarios (s1 to s7, respectively) 


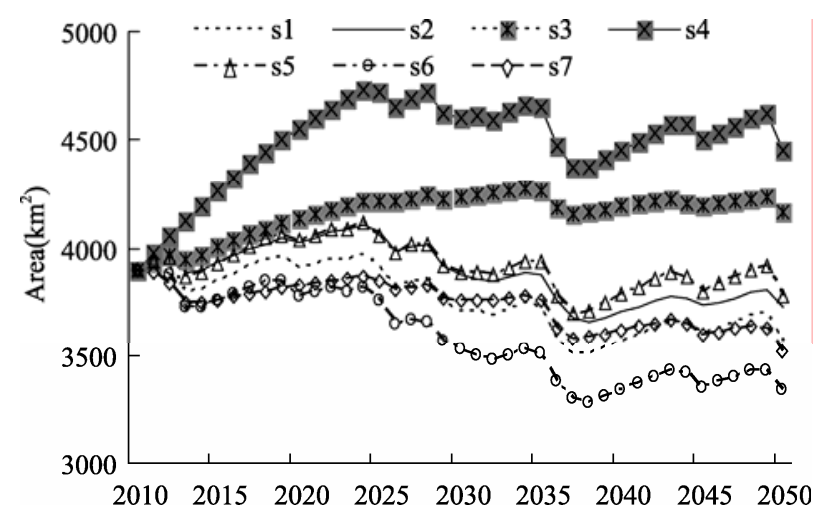

Fig. 7 Comparison of irrigated land area under seven alternative scenarios (s1 to s7)

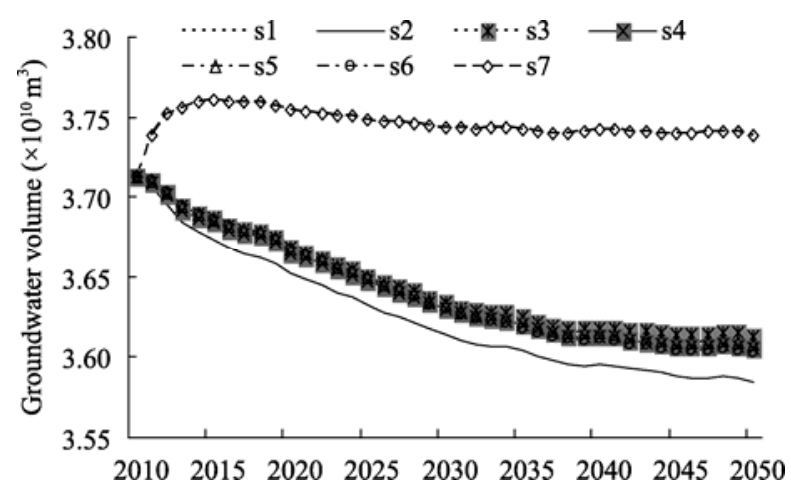

Fig. 8 Comparison of groundwater volume under seven alternative scenarios (S1 to S7)

\subsubsection{Water stress}

The perceived water stress indicates the imbalance between the water supply and the water demand, and demonstrates the vulnerability degree of the system. Figure 6 displayed water stress under alternative scenarios. All the scenarios except scenario 6 are to ease the water stress before 2032. The dispersion degree of the water stress index among scenarios has a decreasing trend, which means that no policies can release the water stress problem in the long run. The release of water stress induces a further expansion of irrigated lands and hence further increase in water demand. For instance, Scenario 4 contributes most to the water stress release in the first decade. It reaches the same degree as that in the basic scenario does in 2035. These results support the hypothesis that serious water deficit problems cannot be solved exclusively by the policies based on the increase of water resources or the water consumption technology improvement, such as the performances form scenarios 2-6. Among these scenarios, the urban water recycling policy is most efficient for reducing the water stress after 2022. It improves the water supply, and then releases the water stress. As for the pumping control policy, it does not worsen the water stress situation, despite the fact that it constrains the water supplement from groundwater and intensifies water stress at first. The differentiation between scenario 7 and scenario 1 keeps amplifying before 2018, and then shrinks.

\subsubsection{Irrigated land}

Irrigation consumes $95 \%$ of the available water in the Manas River Basin. The area of irrigated land reflects the structure change of the water allocation. The change trend of irrigated land area under alternative scenarios is shown in Fig.7. The result indicated that most of the scenarios augment the area of irrigated land, which is displayed in the increasing dispersion degree of the irrigated land area among the scenarios.

Reduction in irrigation water demand can increase the irrigated land area rapidly and extensively. A reduction of $20 \%$ in irrigation water demand per area can increase the area of the irrigated land by about 900 $\mathrm{km}^{2}$. It is observed in many parts of the Manas River Basin that the irrigated land is being expanded by improving irrigation technology. The urban water recycling policy deserves recognition, for it increases the area of irrigated land significantly, and smoothes fluctuations. The reason is that the recycling water is mainly used for irrigation. Both scenarios 2 and 5 are able to increase the area of irrigated land by about 190 $\mathrm{km}^{2}$ during period 2010-2030. Scenario 5 which reduces industrial water demand by $50 \%$ will become more efficient after 2030 because of industry expansion. The contribution of the reservoir building is relatively constrained. The effect of the industrial water demand increasing policy is opposite to that of the industrial water demand reducing policy. It decreases the area of the irrigated land by $190 \mathrm{~km}^{2}$. In case of the pumping control policy, it returns the land irrigated by groundwater to unused land immediately. In the future, the area of irrigated land in scenario 7 will be projected to a level similar to that of the basic scenario with some fluctuations. This is because of the limited available groundwater in the long run. The 
fluctuations are due to the time delay for irrigated land exploration.

\subsubsection{Groundwater}

In Xinjiang, most aquifers are over-exploited, which has led to severe water table declines. The change in groundwater under alternative scenarios is shown in Fig. 8. Among all the alternative scenarios, the pumping control policy (scenario 7) can alleviate groundwater subsidence considerably in the first five years. Then, the alleviation will slightly decrease, under the assumption that irrigation technology improvement reinforces evaporation and cuts down groundwater recharge. On the other hand, the strategies based on the demand sides in scenarios 2-6 can not change the deteriorating trend of the groundwater system. It is generated by the feedback loops of the system. The water saved by the reduction in per capita water demand leads to industry/irrigated land expansion, and vice versa. Among scenarios 2-6, the urban water recycling policy has a better performance, which will ease the groundwater stress by $72 \mathrm{Mm}^{3}$ by 2050. The reservoir building would deteriorate groundwater decline evidently. It would result in a decrease of 209 $\mathrm{Mm}^{3}$ in groundwater. This deterioration is caused by the sacrifice of recharge from the reservoir to the groundwater.

Integrating these 7 scenarios, all water saving technologies increase the area of irrigated land. Scenario 4 is the most efficient method for land cultivation, while the reservoir building designed in scenario 2 is not recommended because it would deteriorate groundwater system. Urban water recycling policy in scenario 3 could stabilize the irrigated land area and alleviate both the groundwater subsidence and water stress. The impacts of scenarios 5 and 6 are comparatively small, for the industry water demand is relatively small. As far as the other groundwater recharge options are concerned, the control on pumping in scenario 7 helps to stop the groundwater level reduction. This resort restricts the irrigated land exploration in the first decade, however, the irrigated land area would eventually remain stable, whether this resort is used or not. To sum up, scenarios 3, 4, 5 and 7, to implement water saving technologies and to control pumping, are effective policies.

\section{Conclusions}

This study applied system dynamics as an effective methodology to organize and integrate existing information available on watershed hydrological processes, water exploitation, water allocation, and water-social-economic interrelation system. Its value lies in its representation of interactions between multiple model components as explicit feedbacks, social-economichydrological balance, and sustainability-focused horizontal integration of model sectors. The study provides a platform to analyze the endogenous impact mechanisms of 6 policies aiming to reduce or minimize the water resource problem while the society is economic-oriented. It is particularly favorable for understanding the unanticipated outcomes. The model's behavior arises from the system's structure rather than from input data or driving functions.

The simulated results suggested that: 1) Supply-driven water exploitation strategies (scenario 2) are not sustainable and they will result in a continual decrease of groundwater; 2) The policies (scenarios 4, 5) for water use efficiency improvement can drive up the economic output but cannot ease water stress in the long run; 3) Urban water recycling policy (scenario 3) stabilizes the irrigated land area and moderates both the groundwater subsidence and water stress; and 4) Constraints on groundwater pumping (scenario 7) will restrict land cultivation in the short run, and can alleviate the decrease of groundwater.

Although a broadly-focused model, with its regional- and annual-resolution, sacrifices accuracy for prediction, its formulation process and simulation results offer a representation of water-socio-economic system and insights into the complexity dynamic evolution. The application of this model may significantly contribute to advances in the sustainable management of water issues in arid land.

Given limitations on time and data, the model is tenable only within a series of assumptions. The lack of effective data and precise information, such as regarding the relationship of water pumping to groundwater and the impact of increasing urban water consumption on water stress, created some uncertainties during the simulation. As an integrated model, it may neglect some potentially important industrial and hy- 
drological processes and seasonal effects. Additions and modifications to the model should be imposed, including the impact of climate change, industry and agriculture specifications, external investment impact, as well as the consideration of water diversion projects.

\section{Acknowledgements}

This work was supported by the National Basic Research Program of China (2010CB951004) and a project of Xinjiang Key Lab of Water Cycle and Utilization in Arid Zone, Xinjiang Institute of Ecology and Geography, Chinese Academy of Sciences (XJYS0907-2009-02).

\section{References}

Ahmad S, Simonovic S P. 2000. System dynamics modeling of reservoir operations for flood management. Journal of Computing in Civil Engineering, 14(3): 190-198.

Ahmad S, Simonovic S P. 2006. An intelligent decision support system for management of floods. Water Resources Management, 20(3): 391-410.

Ahmad S, Prashar D. 2010. Evaluating municipal water conservation policies using a dynamic simulation model. Water Resources Management, 24(13): 3371-3395.

Berkes F, Folke C. 1998. Linking Social and Ecological Systems: Management Practices and Social Mechanisms for Building Resilience. Cambridge: Cambridge University Press.

Cheng W M. 2003. Research on landscape pattern and evolution of Manas River watershed in Xinjiang. PhD Dissertation. Beijing: Institue of Geographic Sciences and Natural Resources Research, Chinese Academy of Sciences.

Cheng W M, Zhou C H, Liu H J, et al. 2006. The oasis expansion and eco-environment change over the last 50 years in Manas River Valley, Xinjiang. Science in China: Series D (Earth Sciences), 49(2): 163-175.

Chow G C, Li K W. 2002. China's economic growth: 1952-2010. Economic Development and Cultural Change, 51(1): 247-256.

Chu J Y, Wang C, Chen J N, et al. 2009. Agent-based residential water use behavior simulation and policy implications: a case study in Beijing city. Water Resources Management, 23(15): 3267-3295.

Compiling Committee Shihezi County Annals. 1994. Shihezi County Annals. Urumqi: Xinjiang People's Publishing House.

de Marsily G. 1986. Quantitative Hydrogeology: Groundwater Hydrology for Engineers. Orlando: Academic Press.

Evans T P, Manire A, de Castro F, et al. 2001. A dynamic model of household decision-making and parcel level landcover change in the eastern Amazon. Ecological Modelling, 143(1-2): 95-113.

Falkenmark M. 1997. Society's interaction with the water cycle: a conceptual framework for a more holistic approach. Hydrological Sciences Journal, 42(4): 451-466.

Fernández J M, Selma M A E. 2004. The dynamics of water scarcity on irrigated landscapes: Mazarrón and Aguilas in south-eastern Spain. System Dynamics Review, 20(2): 117-137.

Ford A. 1999. Modeling the Environment: An Introduction to System Dynamics Modeling of Environmental Systems. Washington DC: Island Press.

Forrester J W. 1961. Industrial Dynamics. Cambridge: MIT Press.

Gastélum J R, Valdés J B, Stewart S. 2010. A system dynamic model to evaluate temporary water transfer in the Mexican Conchos Basin. Water Resource Management, 24(7): 1285-1311.

Gastelum Perez J R. 2006. Analysis of water resources alternatives to improve water allocation on the Conchos Basin during drought situations. PhD Dissertation. Arizona: Department of Hydrology and Water Resource, the University of Arizona.

Gunderson L H, Carpenter S R, Folke P C, et al. 2006. Water RATs (resilience, adaptability, and transformability) in lake and wetland social-ecological systems. Ecology and Society, 11(1): 16.

Han D L, 2001. Xinjiang Artificial Oasis. Beijing: China Environmental Science Press, 1-50.

Li L, Simonovic S P. 2002. System dynamics model for predicting floods from snowmelt in North American prairie watersheds. Hydrological Processes. 16(13): 2645-2666.

Li L, Yakupitiyage A. 2003. A model for food nutrient dynamics of semi-intensive pond fish culture. Aquacultural Engineering, 27(1): 9-38.

Lindh G. 1985. Problems related to growing urban systems from a river basin perspective. In: Lundqvist J, Lohm U, Falkenmark M. Strategies for River Basin Management: Environmental Integration of Land and Water in a River Basin. Dordrecht Holland: Reidel Publishing Company, 337-346.

Ling H B, Xu H L, Fu J Y, et al. 2012. Surface runoff processes and sustainable utilization of water resources in Manas River Basin, Xinjiang, China. Journal of Arid Land, 4(3): 271-280.

Maani K E, Cavana R Y. 2007. Systems Thinking, System Dynamics: Managing Change and Complexity. Auckland: Pearson Education New Zealand.

Naylor T H, Finger J M. 1967. Verification of computer simulation models. Management Science, 14(2): B92-B106.

Office of the Xinjiang Uygur Autonomous Regional Committee, Xinjiang Uygur Autonomous Region People's Government Office. 2005. Xinjiang Brilliant Fifty Years. Urumqi: Xinjiang People's Publishing House.

Ohlsson L, Turton A R. 1999. Social Resource Scarcity the Bottle-neck in Adaptation to Water Scarcity. Water Issues Study Group, School of Oriental and African Studies (SOAS Occasional Paper No. 19). London: University of London.

Rauch W, Bertrand-Krajewski J L, Krebs P, et al. 2002. Mathematical modeling of integrated urban drainage systems. Water Science and Technology, 45(3): 81-94.

Richardson G P. 1991. Feedback Thought in Social Science and Syste $\neg$ ms Theory. Philadelphia: University of Pennsylvania Press.

Richmond B. 1993. Systems thinking: critical thinking skills for the 1990s and beyond. System Dynamics Review, 9(2): 113-133.

Ruth M, Hannon B. 1994. Modeling Dynamic Economic Systems. New York: Springer-Verlag. 
Rykiel Jr E J. 1996. Testing ecological models: the meaning of validation. Ecological Modeling, 90(3): 229-244.

Sánchez-Román R M, Folegatti M V, Orellana-González A M G. 2010. Water resources assessment at Piracicaba, Capivari and Jundiaí River Basins: a dynamic systems approach. Water Resource Management, 24(4): 761-773.

Saysel A K, Barlas Y, Yenigün O. 2002. Environmental sustainability in an agricultural development project: a system dynamics appr o-ach. Journal of Environment Management. 64(3): 247-260.

Senge P M. 1990. The Fifth Discipline: The Art and Practice of the Learning Organization. New York: Doubleday.

Senge P M. 1998. Some thoughts on the boundaries of classical system dynamics. Proceedings of the $16^{\text {th }}$ International Conference of the System Dynamics Society. Albany: System Dynamics Society.

Shihezi Electricity and Water Authority, Manasi River Management Office. 1992. Manasi River Basin Water Conservancy Annals. Shihezi: Shihezi County Annals.

Simonovic S P, Fahmy H. 1999. A new policy analysis modeling approach for water resources. Water Resources Research, 35(1): 295-304.

Statistics Bureau of Xinjiang Production and Construction Corps, Survey Organization of the Corps of National Statistics Bureau. 1990-2007. Xinjiang Production and Construction Corps Statistical Yearbooks 1990-2007. Beijing: China Statistical Press.

Statistics Bureau of Xinjiang Uygur Autonomous Region. 1990-2007. Xinjiang Statistical Yearbooks 1990-2007. Beijing: China Statistical Press.

Sterman J. 2000. Business Dynamics: Systems Thinking and Modeling for a Complex World. New York: Irwin McGraw-Hill.

Survey and Design Institute of Xinjiang Production and Construction
Corps. 1995. General Report on the Manas River Basin Water Resources Use Planning. Urumqi: Survey and Design Institute of Xinjiang Production and Construction Corps.

Survey and Design Institute of Xinjiang Production and Construction Corps. 1997. General Report on the Manas River Basin Planning. Urumqi: Survey and Design Institute of Xinjiang Production and Construction Corps.

Syme G, Hatfield-Dodds S. 2007. The role of communication and attitudes research in the evolution of effective resource management and arrangements. In: Hussey K K, Dovers S. Managing Water for Australia: The Social and Institutional Challenges. Victoria: CSIRO Publishing, 11-22.

Tang Q C, Qu Y G, Zhou Y C. 1992. China's Arid Zone Hydrology and Water Resources. Beijing: Science Press, 60-100.

Tidwell V C, Passell H D, Conrad S H, et al. 2004. System dynamics modeling for community-based water planning: application to the middle Rio Grande. Aquatic Science, 66(4): 357-372.

Wallis J, Chichakly K, Peters S, et al. 1997. STELLA II Technical Documentation. Hanover: High Performance Systems, Inc., 255.

Winz I, Brierley G, Trowsdale S. 2009. The use of system dynamics simulation in water resources management. Water Resource Management, 23(7): 1301-1323.

Xu Z X, Takeuchi K, Ishidaira H, et al. 2002. Sustainability analysis for Yellow River water resources using the system dynamics approach. Water Resources Management, 16(3): 239-261.

Yuan G Y, Qu X L, Li J S. 1995. Agricultural Ecological Environment Protection and Rational Utilization of Resources in Manas River Basin, Xiangjiang. Urumqi: Xinjiang Science and Technology Press, $1-200$. 